\title{
The Prevalence of Behavioral Problems among Secondary School Students in Khartoum State
}

\author{
Dr. Rawaa Abdal-Wahab Mirghani*1 \& Prof. Abdelbagi Daflla Ahmed ${ }^{2}$ \\ ${ }^{1}$ School Psychologist Federal Ministry of Education, Sudan \\ ${ }^{2}$ Dept. of Psychology, Faculty of Arts, University of Khartoum, Sudan
}

\author{
Article History \\ Received: 28.08 .2020 \\ Accepted: 12.09 .2020 \\ Published: 30.09 .2020 \\ Journal homepage:
}

https://www.easpublisher.com/easipbs

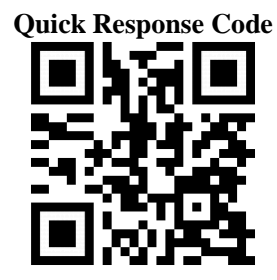

Abstract: The aim of this study is to find out the most prevalent behavioral problems among secondary school students in Khartoum state, as well as to identify differences in behavioral problems according to the following variables: academic level (excellent, good, medium, and weak), and the grade level (first, second, and third), and the residential environment According to the locality (Khartoum, Jabal Awlia, Khartoum North, East Nile, Omdurman, Karary, Umbada), this is in addition to the problems related to gender (male, female), and school type (geographic, model). To achieve these goals, the researchers used the descriptive approach (case study), and all students that were registered by psychological counselors in secondary schools (1851) cases were selected, and the study tool was represented in the case study form used by psychological counselors. To analyze the data, the researchers applied the statistical package for social sciences by using the percentage of answers for each of the research hypotheses. The study reached a set of results, the most important of which are: behavioral problems are spread at different percentages among high school students in Khartoum State (theft $19.4 \%$, lying $19.3 \%$, aggression 16.8. Behavioral problems differ according to the seven localities of Khartoum State, as the results showed that: theft is one of the most prevalent problems in the Khartoum locality $27.2 \%$, and that lack of attention and hyperactivity are the most prevalent problems in Jabal Awliya locality $49.3 \%$, and the most common problems in Khartoum North are; drug-abuse 22.2\%. In the eastern Nile region, the research results showed that emotional problems are among the most common, reaching $20.7 \%$. As for Omdurman locality, the problem of lying was among the most prevalent problems, $22.2 \%$. Behavioral problems differ according to gender (male, female). The results of the research showed that the most prevalent problem in female is theft $72.4 \%$, and among males, emotional problems $47.9 \%$. Behavioral problems differ according to the type of school. The research results showed emotional problems (96.4\%) more prevalent in geographical schools, and theft $22.7 \%$ in model schools. Finally, the research included a number of recommendations, the most important of which are: the necessity and importance of generalizing the psychological counselors in all schools in Sudan.

Keywords: Behavioral Problems, Secondary schools students, Khartoum State.

Copyright (C) 2020 The Author(s): This is an open-access article distributed under the terms of the Creative Commons Attribution 4.0 International License (CC BY-NC 4.0) which permits unrestricted use, distribution, and reproduction in any medium for non-commercial use provided the original author and source are credited.

\section{INTRODUCTION}

The progress of cultural and technological development and the rapid successive changes in various aspects of life have contributed to making the human being more confused and anxious. Perhaps Arab and African societies in general and Sudanese society in particular, are in need of strong people with a normal personal and psychological structure that they can rely on. Sudan has made great strides in the spread of public and secondary education throughout the country. Despite the suffering of educational field from many thorny issues related to the educational environment, the problems of sitting, books and problems of teachers in terms of training, welfare, etc., there are many psychological and educational research indicated the suffering of students from many pressures, which may affect their behavioral and personal structures, as it appears in the form of behavioral problems such as lying, theft, aggression, lack of attention and hyperactivity, in addition to running away from home or school.

Abdelbagi and Hajer (2010) revealed that; behavioral problems hinder all aspects of students' growth, make them fail to achieve their desired goals i.e. threaten the educational process, and harm the family and the rest of the students' surroundings. Schools in the present era are no longer just academic institutions, but have become cultural organizations for young people, in which a vital and necessary interaction 
takes place between various intellectual trends, so school life becomes a form of cultural and intellectual interaction to reach the highest level. For this, its effort should be directed towards preparing students to take responsibility, help them face their problems; this represents the strategic role of the school that distinguishes it from other institutions. The problems of students take many forms: behavioral, psychological, social and academic. That is, what is related to the student's self, related to his family, his cultural or social status, as well as what is related to his academic status.

Although there are so many studies on behavioral problems, there is no study so far that highlights the prevalence of behavioral problems among adolescents in Sudan. The researchers have tried a lot to find statistical studies on behavioral problems in Sudan whose results can be trusted, but most of the reports on the prevalence of behavioral problems mentioned approximate percentages. So, in order to enable specialists to develop effective treatment and preventive programs for behavioral problems, it is necessary to investigate behavioral problems of all kinds and study their relationship with the most common variables.

Based on the foregoing; and through the field work in psychological counseling in some governmental schools in Khartoum State, it was confirmed to researchers that there are many problems that faced secondary school students. The current research focused on the common behavioral problems of high school students in Khartoum State, which the two researchers made an observation through case studies that reached the offices of psychological counselors at the secondary schools.

\section{Theoretical Framework and Previous Studies}

In adolescence, emotions overwhelm their personality and ignite within them, and their moods become strange and intertwined, and conflicting feelings interact in themselves that can be summarized in the following: loneliness, sadness, anxiety, sense of self, anger, depression, low self-esteem and sadness "(Al-Issawi 1998)For all of the above, the stage of adolescence requires a very special treatment in order to develop the personality free from behavioral problems. Based on the experience of researchers in the field of psychological counseling in schools, the stage of adolescence requires calm handling, providing care and compassion for the adolescent, with space to express his opinion, and giving him an opportunity for discussion, so that he has confidence in Self, temperament and personality balance, "The family must bear the effort in building the desired behavior, and the school completes the role of the family in establishing the rules of social behavior through sports, scientific and cultural activities that promote the spirit of fair competition and respect for others" (Al Tayyar, 2009) .Behavioral problems are defined as a type of deviant and repetitive behavior in which laws, values, or rights are violated in society, whether at home, school or among comrades, and it is every form of behavior that does not comply with the norms of normal behavior recognized in the social environment and which reflects on the psychological competence of the teenager And sometimes social-life. The behavioral problems are also " a constant or repetitive pattern of behavior in which the rights of others or the basic values of society and its laws appropriate to the age of adolescence are violated at home, school, among comrades and in society, provided that this behavior is more dangerous than just the usual annoyance or the usual pranks of adolescents, and that it is not a disorder of stray stubbornness (Hammouda, 1991).

There are several classifications of behavioral problems, the most prominent of which is Kwai's classification reported by Jamal Qasim (2000) as follows:

1. Conduct Behavior: They include the types of aggressive verbal and physical behavior, matched by deficiencies in personal relationships with peers and adults in society.

2. Immaturity problems: These are problems that are not compatible with adolescents' chronological age, which include neglect, dullness, mental distraction, daydreams, and sleepiness, lack of speech, short attention span and negativity.

3. Personality problems: These include social withdrawal, anxiety, feelings of shame, inferiority, isolation, feelings of sadness and physical complaints.

4. Social delinquency: This category includes verbal and physical aggression, escaping from school and quarrels. The adolescent child performs this behavior within a group of comrades or within a gang.

Second: Therapeutic counseling: It is the process of helping the individual to discover, understand and analyze himself and his personal, emotional and behavioral problems that lead to poor psychological adjustment and work to solve problems in a way that achieves the best level of harmony and mental health.

The study of Hala Abdel-Azim (2002 ): The Psycho-social Adjustment of Adolescents in Omdurman Locality. The study aimed to find out the psycho-social problems of adolescents at the secondary stage, the sample size was (400) students from public secondary schools, including 225 male and 175 female students, the study used the questionnaire to collect information. The most important results of the study as follows: The psycho-social problems of adolescents at secondary schools are statistically above the average. There is no significant correlation between adolescents' psychosocial problems with monthly income of the family and the adolescent's birth order or the educational level of the parents. There is no difference in adolescent psycho-social problems attributable to age, class, 
housing, employment. The is no significant correlation between the psycho-social problems of the adolescent and the level of her academic achievement with all dimensions except for the following; religion and ethics problems, home and family problems.

Afaf Mohammad Khalafalla (2008): Parental Style of rearing and their relationship to behavioral, school and psychological problems for adolescent at secondary school students in Omdurman locality. The study adopted the correlational descriptive method where the scales of parenting styles and the behavioral problems were used on a sample of (450) students from (10) government schools in Omdurman locality. The study found: There is a positive correlation between parental treatment methods and behavioral, school and psychological problems among adolescent students in secondary schools. Behavioral problems spread in different percentages among adolescent of secondary schools in Omdurman locality, there is no statistically significant differences in behavioral problems according to gender (male, Female) and there is statistically significant differences in the dimensions of psychological and school problems according to school level. There is a statistically significant positive correlation between the total degree of psychological needs and the age of the.

Abdelbagi Dafalla and Hagir Al-Idrisi (2010): Behavioral problems among secondary school students in Khartoum locality and their relationship to parental acceptance / rejection. The study aimed to know the most severe problems (breach of systems and regulations, breach of family standards, problems of order and arrangement, problems of concentration and organization of time) among secondary school students in Khartoum locality. The study also aimed to investigate the relationship of behavioral problems to parental acceptance and rejection (acceptance, hostility, neglect, Rejection) as it aimed to find out the differences in behavioral problems according to some student community variables such as class and gender, the researchers used the correlative descriptive approach. The sample was drawn in a randomized method by selecting (802) students (402) male (400) females, the study tools represented in the scale of behavioral problems, parental acceptance-rejection scale, in addition to a list of bibliographical information sheet. The data were processed using the Statistical Package for Social Sciences applying the following: Ttest, one way analysis of variance, and the Pearson and Spearman correlation coefficient. The study reached a set of results, the most important of which are: Evasion from doing homework And being late to school appointments, talking during classes with colleagues, having a lot of movement in the classroom, and eating inside the classroom are the most spread problems among students. Males outperform females with a statistically significant difference in the problems related to disruption of order and school regulations, and disruption of family and social norms. Females excel in a statistically significant degree than males in problems related to order and arrangement, problems of concentration and time management. The study showed that there is a statistical negative correlation between acceptance and all dimensions of behavioral problems. There is a positive correlation between behavioral problems with hostility, neglect and rejection. The results indicated that third grade students excel in all behavioral problems over first and second level students.

Rawa Abdelwahab Mirghani 2015 study: titled Behavioral problems and their relationship to personality traits among high school students in Khartoum North locality. The study aimed to investigate behavioral problems and their relationship to personality traits among secondary school students in Khartoum North locality, and the differences in behavioral problems among female students according to the grade level (first - second - third), the level of the relationship between parents (good, bad) and the educational level of the parents. The researchers adopted the correlative descriptive method. A sample of (150) female students were randomly selected from the population. The most important results of the study are: Behavioral problems are significantly spread among high school students, and there is a positive correlation between behavioral problems and some personality traits (hyperactivity, attention deficit, emotional problems). There is no significant difference in behavioral problems according to father's education level. There is no significant difference in behavioral problems depending on the level of the relationship between the parents. This study included a number of recommendations, the most important of which is the inclusion of a curriculum on psychological counseling in the educational system.

\section{Commenting On Previous Studies}

The previous studies helped researchers in the following dimensions:

1. Crystallizing the present research problem and defining its dimensions and fields: through extensive access to what has been written in terms of studies and research on the problem chosen by the researchers, which definitely kept them away from repeated research that others had preceded them, and concluded it from difficulties that others may have encountered, and thus previous studies led them to correct research worthy of study..

2. The researchers were able, through previous studies, to determine the tools they used in their research, and were provided with ideas, procedures and tests that they benefited from in solving research problems.

3. Previous studies were a point of strength in research and a new start for a new study, especially when defining the problem because they are strong justifications and arguments for scientific research 
that show the missing scientific gap in scientific research, which would prepare the new research study.

\section{Study Methodology}

This part of the study deals with the methodology used to verify the hypotheses, the description of the study sample, the tool used to collect the information, a review of the procedures by which the study tool was used, and an exposure to the statistical methods that were used to test the study hypotheses. IN order to achieve the objectives of the current study, the researchers adopted the case study approach (descriptive studies), which aims to study the distribution and prevalence of behavioral problems in public secondary schools in Khartoum state according to some variables, the case study can be used as a means of collecting information and data in a descriptive study. As well as generalizing its results to other similar cases, provided that the case is representative of the community to be judged, and this is what the researcher aims to reach (Kandalji, 2018).

\section{Study Population}

The study population means the total group of elements that the researchers seek to generalize on the results related to the studied problem. The study population represents secondary school students in government schools according to the administrative localities in Khartoum state (Khartoum-North, Omdurman, Khartoum, Jabal Awlia, East Nile, Karary, and Ombada. (2019-2020), which consists of 382 schools and the study population, can be described through the following points:

Table (1) the number of students and secondary schools in Khartoum State.

\begin{tabular}{lccccc}
\hline Localities & Male Schools & No. of students & Female Schools & No. of students & Total \\
\hline Khartoum & 23 & 9306 & 30 & 8786 & 18.092 \\
Jabal Awlia & 26 & 8192 & 37 & 14907 & 23.099 \\
Kh. North & 32 & 8345 & 28 & 9958 & 18.303 \\
East-Nile & 50 & 8860 & 54 & 12964 & 21.182 \\
Omdurman & 26 & 6428 & 26 & 7903 & 14.331 \\
Karary & 22 & 9659 & 33 & 8111 & 17.770 \\
Ombada & 25 & 8200 & 23 & 14700 & 22.900 \\
\hline
\end{tabular}

\section{The Study Sample}

The study sample consisted of students who had a case study in the offices of school counselors in government secondary schools in the state of Khartoum.

\section{Study Tools}

The researchers used various tools in order to be able to research the problem of the study and verify its hypotheses. Among the tools that the researchers resorted to are the following: The case studies in the record of the psychological counselors. And a preliminary data form and the records of the results of mid-year of the academic year 2109-2020.

\section{Field Study Procedures}

The researchers wrote a letter to the Statistics Unit at the Ministry of Education to allow them to view the data and address the school administrations to meet the psychological counselors in government schools. The initial data form was also approved, and then the researchers went to the secondary school administration and took a list of the names of the counselors and their schools in which they work as well, with their phone numbers, the researchers took all schools with schools counselors as a total sample from the original study community.

\section{Methods Used In Statistical Analysis}

According to the requirements of the nature of the study hypotheses, the Statistical Packages for Social Sciences (SPSS) program was used using percentages only.

\section{Study Results}

In this part, the findings of the study are presented through the data collection tools used, and methods for their analysis, by presenting each hypothesis and the results related to it, then commenting on it. The following is a presentation of the results of the current study:

\section{The First Hypothesis}

This hypothesis states that (behavioral problems are spread at different percentages and frequencies among secondary schools students in Khartoum state). To find out the answer to this hypothesis, the researchers used the percentage. The results of this procedure showed the following table: 
Table (2) Frequencies and percentages of the most frequent behavioral problems among secondary school students in Khartoum State.

\begin{tabular}{llll}
\hline Order & Name of the problem & Frequency & Percent \\
\hline 1 & Theft & 352 & $19.4 \%$ \\
2 & Lying & 350 & $19.3 \%$ \\
3 & Aggression & 305 & $16.8 \%$ \\
4 & Emotional Problems & 287 & $15.8 \%$ \\
5 & Escape from Home/school & 198 & $10.9 \%$ \\
6 & Hyperactivity and Attention deficit & 174 & $09.6 \%$ \\
7 & Drug abuse & 148 & $08.2 \%$ \\
\hline
\end{tabular}

The researchers put the hypothesis in its current form due to the large number of problems facing the adolescent in his daily life, family, social and school pressures, and the rapid change of life, with the observation of the study community, the researchers found that there are many students who are referred to the school counselor with different problems.

Looking at table (2), it becomes clear that theft and lying are among the most common behavioral problems, reaching 19.3 and $19.4 \%$, followed by aggression $16.8 \%$, emotional problems $15.8 \%$, followed by running away from home / school $10.9 \%$, lack of attention and hyperactivity $09.6 \%$ and finally drugabuse $08.2 \%$. It should be noted that aggression was ranked third among the most common behavioral problems, reaching $16.8 \%$. It is rumored among psychological counselors and teachers that aggression is the most widespread behavioral problem, and this is not correct according to the results of the current study. Theft is a silent behavior, while aggression is a noisy behavior. The correct answer is that theft (19.4\%) is one of the most common behavioral problems in government secondary schools in Khartoum State, followed immediately by lying $19.3 \%$.

\section{The Second Hypothesis}

The second hypothesis states that (behavioral problems differ according to different localities in the state of Khartoum by virtue of the different variables that distinguish each locality from the other). To answer this hypothesis, the researchers used the percentage, and the results of this procedure were shown in Table (3):

Table (3) Frequency and percentage of behavioral problems according to the locality in which students study

\begin{tabular}{|c|c|c|c|c|c|c|c|c|c|c|c|c|c|c|}
\hline \multirow[t]{2}{*}{ Locality } & \multicolumn{2}{|c|}{ Theft } & \multicolumn{2}{|c|}{ Lying } & \multicolumn{2}{|c|}{ Aggression } & \multicolumn{2}{|c|}{ Emotional } & \multicolumn{2}{|c|}{ Escaping } & \multicolumn{2}{|c|}{ Hyperactivity } & \multicolumn{2}{|c|}{ Drug-abuse } \\
\hline & No. & $\%$ & No. & $\%$ & No. & $\%$ & No. & $\%$ & No. & $\%$ & No. & $\%$ & No. & $\%$ \\
\hline Khartoum & 14 & 04.8 & 08 & 05.4 & 12 & 06.8 & 31 & 15.6 & 43 & 14.0 & 22 & 06.8 & 96 & 27.2 \\
\hline Jabal Awlia & 75 & 26.1 & 73 & 49.3 & 45 & 25.8 & 43 & 21.7 & 72 & 23.6 & 63 & 18.0 & 42 & 11.9 \\
\hline Kh. North & 64 & 22.2 & 02 & 01.3 & 36 & 20.6 & 17 & 08.5 & 35 & 11.4 & 34 & 09.7 & 21 & 05.9 \\
\hline East-Nile & 58 & 20.2 & 08 & 05.4 & 17 & 09.7 & 41 & 20.7 & 58 & 19.0 & 53 & 15.1 & 43 & 12.1 \\
\hline Omdurman & 23 & 08.1 & 27 & 18.2 & 24 & 13.7 & 40 & 20.2 & 56 & 18.3 & 78 & 22.2 & 65 & 18.4 \\
\hline Karary & 13 & 04.5 & 09 & 10.8 & 16 & 09.1 & 17 & 08.5 & 18 & 05.9 & 65 & 18.5 & 47 & 13.3 \\
\hline Ombada & 40 & 13.9 & 21 & 14.1 & 24 & 13.7 & 09 & 04.5 & 23 & 07.5 & 35 & 01.0 & 38 & 10.7 \\
\hline Total & 287 & 100 & 148 & 100 & 174 & 100 & 198 & 100 & 305 & 100 & 350 & 100 & 352 & 100 \\
\hline
\end{tabular}

It is evident from the above table that behavioral problems are widespread in Jabal Awlia locality compared to other localities in Khartoum state, as lying problems $(49.3 \%)$ are the highest, followed by theft $(26.1 \%)$, aggression $(25.8 \%)$ and escaping home $(23.6 \%)$. While Khartoum State excels in the high rate of drug abuse (27.2\%), and Omdurman locality has the problem of hyperactivity (22.2\%).

\section{The Third Hypothesis}

This hypothesis postulates that (behavioral problems differ according to the type of school (Model, geographical?) To answer this hypothesis, the researchers used the percentage, and the results of this hypothesis showed in the following table:

Table (4): Frequency and percentages of behavioral problems according to the type of school in which students study (Model, geographical)

\begin{tabular}{|c|c|c|c|c|c|c|c|c|c|c|c|c|c|c|}
\hline \multirow[t]{2}{*}{$\begin{array}{l}\text { Type of } \\
\text { School }\end{array}$} & \multicolumn{2}{|c|}{ Theft } & \multicolumn{2}{|c|}{ Lying } & \multicolumn{2}{|c|}{ Aggression } & \multicolumn{2}{|c|}{ Emotional } & \multicolumn{2}{|c|}{ Escaping } & \multicolumn{2}{|c|}{$\begin{array}{l}\text { Hyperactivit } \\
\mathbf{y}\end{array}$} & \multicolumn{2}{|c|}{$\begin{array}{l}\text { Drug- } \\
\text { abuse }\end{array}$} \\
\hline & No. & $\%$ & No. & $\%$ & No. & $\%$ & No. & $\%$ & No. & $\%$ & No. & $\%$ & No. & $\%$ \\
\hline Geog. & 272 & 77.2 & 301 & 86.0 & 273 & 89.5 & 191 & 96.4 & 149 & 85.6 & 148 & 100 & 239 & 83.2 \\
\hline Model & 080 & 22.7 & 049 & 16.0 & 032 & 16.0 & 077 & 3.50 & 025 & 14.3 & 000 & 000 & 048 & 16.7 \\
\hline
\end{tabular}

The researchers formulated the above hypothesis in relation to the different characteristics of each type of school, as these characteristics in turn lead to a difference in terms of academic achievement, 
individual differences in intelligence, educational methods, even teacher qualifications, and the school environment in general.

It can be observed that the result of this hypothesis agreed with the researchers' expectations, looking at Table (4), as the geographical schools outperformed with a very high percentage in behavioral problems over the model schools, where the lack of attention and hyperactivity was at the top of the list by $100 \%$, and the model schools did not record any case of lack of attention and hyperactivity. After this comes the emotional problems (depression, anxiety, fear, anger), with a score of $96.4 \%$ for geography and $3.50 \%$ for model schools, followed by aggression, where the result in geographical schools was $89.5 \%$ and model $16 \%$, then lying $86 \%$ for geography and $14 \%$ for model schools, drug abuse $83.2 \%$ For geography, $16.7 \%$ for model schools, and finally $77.2 \%$ for theft for geographic and $22.7 \%$ for model schools.

\section{The Fourth Hypothesis}

This hypothesis states that (behavioral problems differ according to the gender of secondary schools students by virtue of the characteristics that distinguish each gender?) To answer this hypothesis, the researchers used the percentage, and the results of this showed in the following table:

Table (5) Frequency and percentages of different behavioral problems according to the gender of students (female, male)

\begin{tabular}{|c|c|c|c|c|c|c|c|c|c|c|c|c|c|c|}
\hline \multirow{2}{*}{$\begin{array}{l}\text { Gender of } \\
\text { students }\end{array}$} & \multicolumn{2}{|c|}{ Theft } & \multicolumn{2}{|c|}{ Lying } & \multicolumn{2}{|c|}{ Aggression } & \multicolumn{2}{|c|}{ Emotional } & \multicolumn{2}{|c|}{ Escaping } & \multicolumn{2}{|c|}{$\begin{array}{l}\text { Hyperactivit } \\
\text { y }\end{array}$} & \multicolumn{2}{|c|}{ Drug-abuse } \\
\hline & No. & $\%$ & No. & $\%$ & No. & $\%$ & No. & $\%$ & No. & $\%$ & No. & $\%$ & No. & $\%$ \\
\hline Male & 167 & 58.1 & 012 & 08.1 & 096 & 55.1 & 103 & 52.0 & 176 & 57.7 & 204 & 58.2 & 255 & 72.4 \\
\hline Female & 120 & 41.8 & 136 & 91.8 & 078 & 44.8 & 095 & 47.9 & 129 & 42.2 & 146 & 41.7 & 097 & 27.5 \\
\hline
\end{tabular}

The researchers formulated the hypothesis in this way due to the difference in the characteristics of gender, and accordingly the way of thinking and interests differ for each group, so what females usually occupy does not work for males, and with the observation of the study community, the researchers noticed a difference in the types of behavioral problems between boys and girls. It is noticed from Table (5) that theft was at the top of the behavioral problems for girls with $72.4 \%$ and for males $27.5 \%$, while lack of attention and hyperactivity was the most common among males $91.8 \%$ compared to females, $8.1 \%$, also the percentage of lying was high among females, $85.2 \%$ of them in Males $41.7 \%$, followed by drug abuse, the recurrence of the problem also exceeded the researchers 'expectations, especially drug abuse among females 58.1, while males 41.8 , followed by aggression, and its prevalence among females was $57.7 \%$ and males $42.2 \%$. As for escaping from home and school, females got $55.1 \%$ and males $44.8 \%$.

\section{The Most Important Findings of the Study}

1. Behavioral problems are prevalent among high school students in Khartoum State, with high percentages.

2. There are differences between the localities of Khartoum state in terms of the type of behavioral problems.

3. There are differences between secondary school students according to the school level (first, second, and third) in terms of the type of behavioral problems.

4. There are differences between secondary school students (geographic, model) in terms of the type of behavioral problems.

\section{Recommendations}

Based on the results of the study, the researchers set out below some recommendations that they hope will have an actual and practical impact to address these problems among high school students, and they are as follows:

1. Taking care of secondary school students and finding out about their problems and working on solving them by scientific methods so that they do not hinder their scientific life and their academic achievement.

2. Activating the role of psychological counselors in schools by training the counselor and providing him with counseling programs and material capabilities.

3. Designing counseling programs for secondary school students in light of these problems, taking into account their need and the necessity of implementing these programs and considering them as part of the academic programs.

4. Psychotherapy is one of the means to eliminate these problems, and it includes discovering problems with the help of psychologists.

5. A psychological and social counselor should be employed for the purpose of psychological counseling in every school in Khartoum State.

\section{REFERENCES}

1. Abdel-Azim, H. (2002). The Psychological and Social adjustment of Adolescents in Omdurman Locality, University of Khartoum, unpublished master's thesis.

2. Abdelbagi \& Hajer (2010). Behavioral problems among high school students in Khartoum locality and their relationship to parental acceptance / rejection. Ministry of General Education Journal, (13), PP: 213-245. 
3. Abdelwahab, R. (2018). Adolescents' behavioral problems and their relationship to the mother's work in Omdurman locality. Master Thesis, Faculty of Arts, University of Khartoum.

4. Afaf Muhammad, K. A. (2008). Styles of parental rearing and its relationship to behavioral, psychological and scholastic problems of among students in the secondary schools of Omdurman locality, PhD thesis, Neelain University.

5. Aladdin, K. (2012). Family Counseling and Psychotherapy, "The Systematic Contact Perspective". Arab Thought House. Cairo.
6. Al-Tayyar, \& Al-Anoud, M. S. (1983). How to win a teenager and prepare him for a successful marriage, 1st floor, Al-Hadara Publishing and Distribution House, Riyadh.

7. Hammouda, \& Abdel-Rahman, M. (1991): The psychological and social development of children and adolescents, Cairo.

8. Jamal Gasim et al (2000). Behavioral Disorders, Amman, Dar Safa. 